\title{
Effect of gum tragacanth on rheological and physical properties of a flavored milk drink made with date syrup
}

\author{
Maryam Keshtkaran, ${ }^{*}$ Mohammad Amin Mohammadifar, $\dagger^{1}$ Gholam Hassan Asadi, ${ }^{*}$ Reza Azizi Nejad, ${ }^{*}$ \\ and Sima Balaghił \\ *Department of Food Science and Technology, Faculty of Agriculture, Islamic Azad University, Science and Research Branch, 1 \\ 477893855 Tehran, Iran \\ †Department of Food Science and Technology, National Nutrition and Food Technology Research Institute, Faculty of Nutrition Sciences \\ and Food Technology, Shahid Beheshti University of Medical Sciences, PO Box 19395-4741, Tehran, Iran \\ $\ddagger$ School III-Process Sciences, Institute of Food Technology and Food Chemistry, Field of Food Rheology, Technische Universität Berlin, \\ Königin-Luise Str. 22, D-14195 Berlin, Germany
}

\begin{abstract}
Date syrup as a nutritional additive and safe alternative to added sugar is one of the best choices for milk flavoring. In this study, a flavored milk beverage was formulated using date syrup for flavoring the product and gum tragacanth to obtain an acceptable mouth feel. Steady shear and dynamic oscillatory rheological properties of the samples contained 3 concentrations $(0$, $0.1,0.2$, and $0.3 \%, \mathrm{wt} / \mathrm{wt}$ ) of 2 types of gum tragacanth (Astragalus gossypinus and Astragalus rahensis) which at $3^{\circ} \mathrm{C}$, were studied. Particle size distribution and colorimetric assays were determined by laser diffractometry and using reflection spectrometer, respectively. Sensory analysis was performed with 25 semitrained panelists, using a 5-point hedonic scale. The results showed that viscoelastic properties, flow behavior parameters, particle size, and color parameters $\left(\mathrm{L}^{*}, \mathrm{a}^{*}\right.$, and $\mathrm{b}^{*}$, where $\mathrm{L}^{*}$ represents lightness, $\mathrm{a}^{*}$ represents the redness/greenness quality of the color, and $b^{*}$ represents the yellowness and blueness quality of the colors) were significantly affected by the concentration of the gum tragacanth and the severity of this effect was influenced by the type of gum. The use of appropriate type and concentration of gum tragacanth in date milk formulation can improve the texture and mouth feel by affecting on particle size and the flow behavior of this product.
\end{abstract}

Key words: date milk beverage, date syrup, gum tragacanth, rheology

\section{INTRODUCTION}

In recent years, dairy food industries have looked to develop new milk-based beverages and products

\footnotetext{
Received July 14, 2012.

Accepted November 29, 2012.

${ }^{1}$ Corresponding author: mohamdif@ut.ac.ir or mohamadif@sbmu.
} ac.ir beyond traditional dairy products to meet consumer demand by addressing health concerns through fortification and combining added-value ingredients into drinks (Arancibia et al., 2011; Cadena et al., 2012). Food formulations are complex and colloidal systems for which their organoleptic properties are adjusted to agree with current fashions by means of structureforming additives, flavorings, and colorings (Mollet, 2001; Yanes et al., 2002; Telcioglu and Kayacier, 2007; González-Tomás et al., 2009). Artificial flavorings and also large amounts of added sugar are the 2 main disadvantages of many formulated milk-based beverages. Many researchers have reached the conclusion that the food and beverages high in added sugars have an adverse effect on diet quality and dietary references intake, especially for children (Frary et al., 2004; Kranz et al., 2004). Among all types of flavors, date syrup (DS) as a natural and nutritional additive is one of the best choices for milk flavoring and a safe alternative to added sugar. Date (Phoenix dactylifera) fruits are important source of carbohydrates $(\sim 70-80 \%)$ and provide energy in the form of easily absorbable simple sugars: mainly glucose, sucrose, and fructose. Chemical composition showed that the flesh of dates has good nutritional value, based on its dietary fibers, minerals, vitamins, natural antioxidants, and other bioactive compounds (Al-Farsi et al., 2007; Elleuch et al., 2008). Date syrup as a naturally sweet juice is made from fresh date that has a golden color, caramel-like flavor and a delicious taste (Hobani, 1998). Averaged chemical composition (weight \%) of DS (degrees Brix of 82) was reported as follows: moisture content: 16.5, proteins: 1.45, glucose: 38.2 , fructose: 39.4 , and ash: 1.6 (Al-Hooti et al., 2002). It was shown that using DS to make some products such as halwa-ardeh, low-fat frozen yogurt dessert, and low caloric cakes resulted in successfully replacing sugar and also improving technofunctional properties of the formulated product (Tufail et al., 2002; Razavi et al., 2007; Milani and Koocheki, 
2011). Sidhu et al. (2003) and furthermore Al-Eid et al. (2010) showed that using DS as a substrate for baker's yeast production resulted in excellent-quality yeasts to be used in the industry baking. As thickening, gelling, and stabilizing agents, hydrocolloids make an important contribution to numerous food and beverage products. In beverages, hydrocolloids can ensure excellent suspension of particles, increasing viscosity, giving desirable body and exceptional mouth feel, improving sensorial properties, and enable fiber addition for natural-label beverages (Grindrod and Nickerson, 1968; Hollowood et al., 2002; Gatade et al., 2009). The knowledge of protein-polysaccharide interactions is of great importance in the control of structure and texture of manufactured foods (Dickinson, 1995). It was shown that the understanding of noncovalent interactions between milk proteins and polysaccharides can be used by food scientists to design and fabricate dairy-based beverages with novel or improved properties (Schmitt et al., 1999; McClements, 2005; Spagnuolo et al., 2005; Tijssen et al., 2007). Many factors such as $\mathrm{pH}$, ionic strength, protein-polysaccharide ratio, and total concentration of biopolymers affect thermodynamic and functional properties of protein-polysaccharide systems (Weinbreck, 2004). In acidic dairy beverages, anionic hydrocolloids such as pectin, $\lambda$-carrageenan, carboxyl methyl cellulose, and gum tragacanth $(\mathbf{G T})$ interact with positively charged casein micelles and whey proteins (Hansen, 1993; Everett and McLeod, 2005). At neutral $\mathrm{pH}$, some proteins such as $\kappa-\mathrm{CN}$ with positively charged regions or $\beta$-CN with hydrophobic groups bind (noncovalently) to the sulfated and hydrophobic groups of hydrocolloids (Snoeren et al., 1975). Gum tragacanth is a hydrocolloid that has been used in a broad range of applications in foods, pharmaceuticals, cosmetics, and diverse industrial uses (Glicksman, 1983; Ghorbani Gorji et al., 2010). Gum tragacanth can be described as a complex, acidic, highly branched, heterogeneous polysaccharide, which consists of 2 major fractions: tragacanthin (water soluble) and bassorin (water swellable), which have quite different rheological properties (Anderson, 1989; Mohammadifar et al., 2006). Balaghi et al. (2011) suggested that various species of gum GT have different chemical compositions and physicochemical properties. Extensive studies have been carried out on GT. Effects of GT on rheological properties of milk proteins were studied in both model system and real dairy beverages (Samavati et al., 2011; Hatami et al., 2012). Previous studies showed that GT obtained from Astragalus gossypinus (AG) can stabilize acidified dairy products and beverages such as doogh, kashk, and yogurt by increasing the viscosity of the continuous phase and formation of soluble protein-polysaccharide complexes (Aziznia et al., 2008; Ghorbani Gorji et al., 2010; Ghorban Shiroodi et al., 2011).

The rheological properties of fluid foods are required to predict and control the quality of products, process calculation, and design of equipment (Steffe, 1996; Metzger, 2006). Although the effect of some hydrocolloids on rheological properties of some acidified dairy products have been studied by several researchers, just a few studies have dealt with the role of polysaccharide functionality in texturizing nonacid dairy products and also our knowledge of the correlation between particle size distribution, rheological properties, and flavor release and other sensory attributes of dairy beverages remains limited (Spagnuolo et al., 2005; Tijssen, et al., 2007; Kiani et al., 2008; Ghorbani Gorji et al., 2010). Nowadays, the demand for functional foods and beverages is rising. Moreover, the adverse effects of flavored milk beverage consumption formulated with artificial flavorings and also large amounts of added sugar are becoming more important for consumers. Given the above considerations, the first aim of this study was to introduce DS as a natural flavoring agent and sweetener for producing a healthy and nutritious flavored milk beverage with lower amounts of added sugar. The second objective was to study the effect of different concentrations of GT exudates from AG and Astragalus rahensis (AR) on steady shear and dynamic oscillatory rheological properties, particle size distribution, and color and sensory properties of the mentioned date milk beverage.

\section{MATERIALS AND METHODS}

\section{Materials}

Two types of Iranian GT exudated by AG and AR were used in this study, collected from plants growing in different provinces of Iran. The raw gums were ground and sieved. Powdered gums with mesh size between 200 and $500 \mu \mathrm{m}$ were used in the current experiment. Standardized milk (2.5\% fat) and DS (degrees Brix = 82 ) were kindly provided by Pegah Dairy Co. (Tehran, Iran).

\section{Sample Preparation}

Samples were prepared by gentle mixing of the DS $(10 \%$, wt $/ w t)$, sugar $(2 \%$, wt/wt) and 2 types of GT powder (AG and AR; 0, 0.1, 0.2, and $0.3 \%$, wt/wt) with milk in $100-\mathrm{mL}$ bottles. The samples were then preheated to $40^{\circ} \mathrm{C}$, homogenized at $180 \times 10^{5} \mathrm{~Pa}$ (APV 1000 laboratory homogenizer; SPX APV, Silkeborg, Denmark), pasteurized in a bain-marie $\left(75^{\circ} \mathrm{C}\right.$ for 5 $\min$ ), cooled to $10^{\circ} \mathrm{C}$, and stored at $3^{\circ} \mathrm{C}$. 


\section{Rheological Measurements}

Steady and dynamic shear rheological measurements were performed with a Physica MCR 301 rheometer (Anton Paar GmbH, Graz, Austria) using a double concentric cylinder geometry with a radius ratio of 1.035 at $3^{\circ} \mathrm{C}$. To ensure that each sample had identical shear histories, the solution was presheared at a shear rate of $100(1 / \mathrm{s})$ for $30 \mathrm{~s}$ and left standing for $10 \mathrm{~min}$ to allow structure recovery and temperature equilibration. The temperature control was carried out with a Peltier system equipped with a fluid circulator. In the experiments, the samples were covered with a solvent trap to prevent evaporation. The power law model was used to describe the rheological properties of solutions over mid-range shear rates $\left(1-50 \mathrm{~s}^{-1}\right)$. The flow behavior index $(n)$ and consistency coefficient $(m)$ values were obtained by fitting experimental data to the Ostwald model:

$$
\tau=\mathrm{m}^{\dot{\gamma}_{\mathrm{n}}}
$$

where $\tau$ is the shear stress $(\mathrm{Pa}), \dot{\gamma}$ is the shear rate $\left(\mathrm{s}^{-1}\right)$ $\mathrm{m}$ is the consistency coefficient $\left(\mathrm{Pa} \cdot \mathrm{s}^{\mathrm{n}}\right)$ and $\mathrm{n}$ is the flow behavior index (dimensionless). A frequency sweep was performed from 0.01 to $1,000 \mathrm{~Hz}$ at a constant strain of $1 \%$ that was in the linear viscoelastic range obtained from an amplitude sweep for the damping factor (tan $\delta)$ :

$$
\tan \delta=\mathrm{G}^{\prime \prime} / \mathrm{G}^{\prime}
$$

where $\delta=$ a phase displacement angle or phase change angle, $\mathrm{G}^{\prime}=$ elastic modulus, and $\mathrm{G}^{\prime \prime}=$ viscous modulus (Steffe, 1996; Metzger, 2006).

\section{Particle Size Analysis}

The particle size distributions of samples were determined at room temperature with a laser diffraction particle size analyzer equipped with an accessory Hydro 2000S (A) small volume automated wet dispersion accessory (Malvern Mastersizer 2000 particle size analyzer; Malvern Instruments Ltd., Worcestershire, UK). Size measurements are reported as the volumeweighted mean diameter $\left[\mathbf{D}_{(4,3)}\right]$ :

$$
\mathrm{D}_{(4,3)}=\sum \mathrm{n}_{\mathrm{i}} \mathrm{d}_{\mathrm{i}}^{4} / \sum \mathrm{n}_{\mathrm{i}} \mathrm{d}_{\mathrm{i}}^{3}
$$

and surface-weighted mean diameter $\left[\mathbf{D}_{(3,2)}\right]$ :

$$
\mathrm{D}_{(3,2)}=\sum \mathrm{n}_{\mathrm{i}} \mathrm{d}_{\mathrm{i}}^{3} / \sum \mathrm{n}_{\mathrm{i}} \mathrm{d}_{\mathrm{i}}^{2}
$$

where $n_{i}$ is the number of particles with $d_{i}$ diameter.

Span is the distribution width and has no relation to mean particle diameter (d), which was calculated using the following equation:

$$
\text { Span }=\frac{d(0.9)-d(0.1)}{d(0.5)} .
$$

Absolute deviation from the median, which is an indicative of polydispersity, was also reported as uniformity $(\mathrm{U})$, where $\mathrm{i}$ is the number of particles and $\mathrm{v}_{\mathrm{i}}$ is the volume of the number of particles existing between the 2 consecutive diameters (McClements, 2005):

$$
\mathrm{U}=\frac{1}{\mathrm{~d}(0.5)} \frac{\sum \mathrm{iv}_{\mathrm{i}}\left|\mathrm{d}(0.5)-\mathrm{d}_{\mathrm{i}}\right|}{\sum \mathrm{iv}_{\mathrm{i}}} .
$$

\section{Color Measurement}

The $\mathrm{L}^{*}, \mathrm{a}^{*}$, and $\mathrm{b}^{*}$ values (where $\mathrm{L}^{*}$ represents lightness, $a^{*}$ represents the redness/greenness quality of the color, and $b^{*}$ represents the yellowness and blueness quality of the colors) were determined for samples with a Color-Eye 7000A reflectance spectrophotometer (CPS Color Pty Ltd., Parramatta, NSW, Australia). The instrument has $\mathrm{d} / 8$ geometry with a 6 integrating sphere and a pulsed xenon lamp. Reflectance data were collected over the full wavelength range of the instruments (360-750 nm, 10-nm interval) with a specular component included through a small area view (SAV) aperture size. The results were expressed in accordance with the International Commission on Illumination (CIE) color space (CIELAB) system with reference to illuminant D65 and a visual angle of $10^{\circ}$. The CIE $\mathrm{L}^{*} \mathrm{a}^{*} \mathrm{~b}^{*}$ space uses the 3 terms $\mathrm{L}^{*}, \mathrm{a}^{*}$, and $\mathrm{b}^{*}$ to represent color. For $\mathrm{L}^{*}, 100$ represents a perfect white sample and 0 a perfect black; for $\mathrm{a}^{*}$, positive values denote redness and negative values denote greenness; for $b^{*}$, positive values denote yellowness and negative values denote blueness, recommended by the International Commission on Illumination (Gilchrist and Nobbs, 2000).

\section{Sensory Evaluation}

Sensory evaluation of samples was carried out with a 25 -member panel $(\mathrm{n}=25 ; 18$ females and 7 males, ages 22 to $37 \mathrm{yr}$ ) who were graduate students of the Department of Food Science and Technology (Shahid Beheshti University, Tehran, Iran) with previous knowledge on sensory evaluation of dairy and dairy-associated products. Samples were analyzed for appearance, color, odor, consistency, taste, and overall acceptability. A 
5 -point hedonic scale was provided to the panelists. The scores were from $5=$ very good to $1=$ undesirable. Mean scores for each attribute were calculated for comparison of the samples. The laboratory was equipped with 5 separate containers having mineral drinking water inside, for mouth rinsing between tests (Watts et al., 1989).

\section{Statistical Analysis}

The data reported in all of the tables are the means of triplicate observations. Analysis of variance was used for data analysis (SPSS 16; IBM SPSS Statistics, Chicago, IL). When $F$-values were significant $(P<$ 0.05) in ANOVA, Duncan's multiple range test were used to compare treatment means. Pearson correlationcoefficient analyses were used to evaluate potential relations between all parameters experimented.

\section{RESULTS AND DISCUSSION}

\section{Rheological Measurements}

Typical flow curves for the DS evaluated at 3, 25, and $45^{\circ} \mathrm{C}$ are shown in Figure 1. Accordingly, a clearly Newtonian behavior was observed with the DS at all temperatures. An earlier study had also shown that DS have Newtonian flow behavior at most temperatures; increasing the temperature caused a decrease in the apparent viscosity of the samples (Hobani, 1998).

According to Figure 2, date milk beverage (DMB) without GT showed Newtonian flow behavior. However, addition of GT to the DMB changed the flow behavior of the system to shear-thinning behavior.

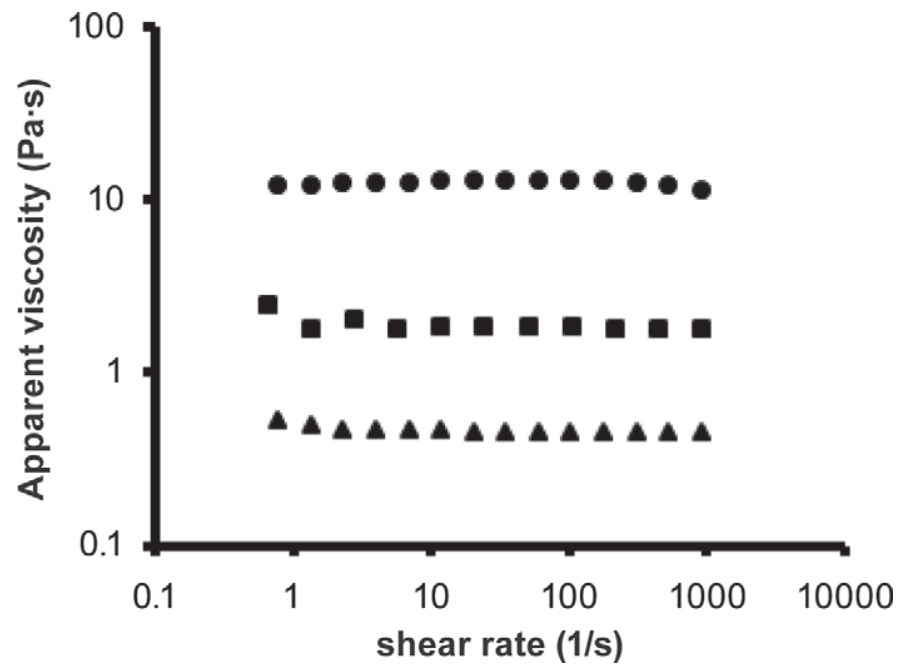

Figure 1. Flow curves of date syrup. $\boldsymbol{\Delta}=$ elastic modulus $\left(\mathrm{G}^{\prime}\right)$ $45^{\circ} \mathrm{C} ; \boldsymbol{\square}=\mathrm{G}^{\prime} 25^{\circ} \mathrm{C} ; \bullet=\mathrm{G}^{\prime} 3^{\circ} \mathrm{C}$.
Similar results were reported by other authors for various dairy products. Telcioglu and Kayacier (2007) and Dogan and Kayacier (2004) investigated the rheological properties of salep drink and found that the samples showed shear-thinning behavior regardless of preparation of samples with sweeteners and milk type. Similarly, Köksoy and Kılıç (2003) reported that ayran sample viscosity decreased when shear rate increased. Increasing the concentration of GT caused an increase of about 10- to 19-fold in apparent viscosity of the samples. The difference in viscosity with increasing shear rate was a decrease of about 3- to 4-fold. Samples with AG in different concentrations showed a higher apparent viscosity more than samples with $\mathrm{AR}$ in the same concentrations. Astragalus gossypinus increased the apparent viscosity of the system more than that of AR. The power-law model was closely fitted to the flow curves of the DMB. The parameters of this model are summarized in Table 1; it was seen that with increasing GT concentration the consistency coefficient increased, but the flow behavior index showed a decreasing trend
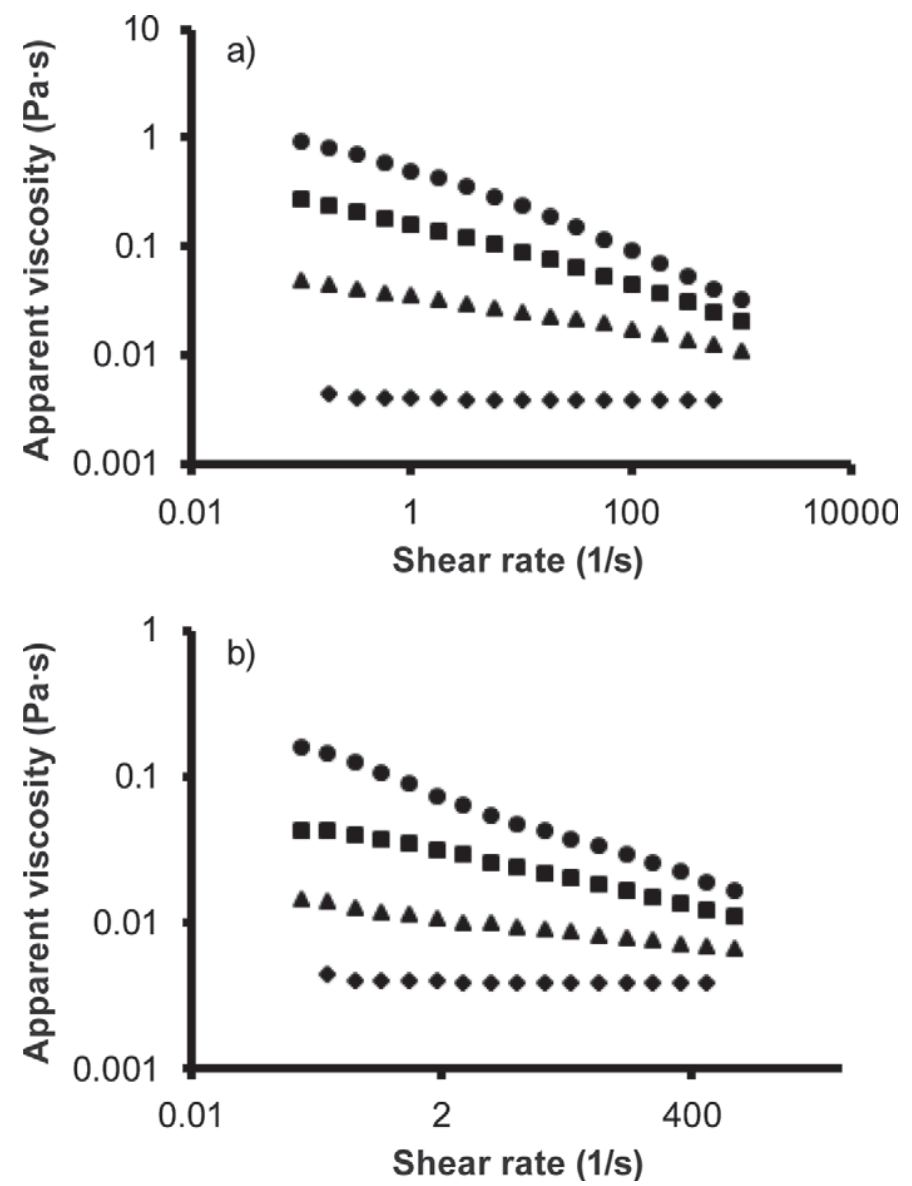

Figure 2. Flow curves of samples with 2 types and different concentrations of gum tragacanth $(\mathrm{GT})$ at $3^{\circ} \mathrm{C}$. (a) Astragalus gossypinus; (b) Astragalus rahensis. $\bullet=0 \% ; \boldsymbol{\Lambda}=0.1 \% ; \mathbf{\square}=0.2 \% ; \bullet=0.3 \%$. 
Table 1. Parameters related to the power-law model for samples with 2 types and 3 concentrations of gum tragacanth $(\mathrm{GT})^{1}$

\begin{tabular}{|c|c|c|c|c|c|c|c|c|}
\hline \multirow{2}{*}{$\begin{array}{l}\text { GT concentration } \\
(\%)\end{array}$} & \multicolumn{4}{|c|}{ Astragalus rahensis } & \multicolumn{4}{|c|}{ Astragalus gossypinus } \\
\hline & $\mathrm{m}\left(\mathrm{Pa} \cdot \mathrm{s}^{\mathrm{n}}\right)$ & $\mathrm{n}$ & $\mathrm{R}^{2}$ & SD & $\mathrm{m}\left(\mathrm{Pa} \cdot \mathrm{s}^{\mathrm{n}}\right)$ & $\mathrm{n}$ & $\mathrm{R}^{2}$ & $\mathrm{SD}$ \\
\hline 0.1 & $0.012^{\mathrm{c}}$ & $0.92^{\mathrm{a}}$ & 0.99 & 0.00048 & $0.035^{\mathrm{c}}$ & $0.85^{\mathrm{a}}$ & 0.99 & 0.0011 \\
\hline $\begin{array}{l}0.1 \\
0.2\end{array}$ & $0.036^{\mathrm{b}}$ & $0.83^{\mathrm{b}}$ & 0.99 & 0.0026 & $0.161^{\mathrm{b}}$ & $0.74^{\mathrm{b}}$ & 0.99 & 0.014 \\
\hline 0.3 & $0.095^{\mathrm{a}}$ & $0.76^{\mathrm{c}}$ & 0.99 & 0.0038 & $0.517^{\mathrm{a}}$ & $0.65^{\mathrm{c}}$ & 0.99 & 0.061 \\
\hline
\end{tabular}

${ }^{a-c}$ Means with different letters within a column differ significantly $(P<0.05)$.

${ }^{1} \mathrm{~m}=$ consistency coefficient; $\mathrm{n}=$ flow behavior index (dimensionless).

(Ghorbani Gorji et al., 2010). The DMB containing AG had higher values of consistency coefficient and lower values of flow index than DMB containing AR. Balaghi et al. (2010) reported that various types of tragacanth contain different proportions of soluble and insoluble (less-soluble) components and AG aqueous dispersion $(1.5 \%)$ had a much higher consistency coefficient than that of AR aqueous dispersion (Balaghi et al., 2010).
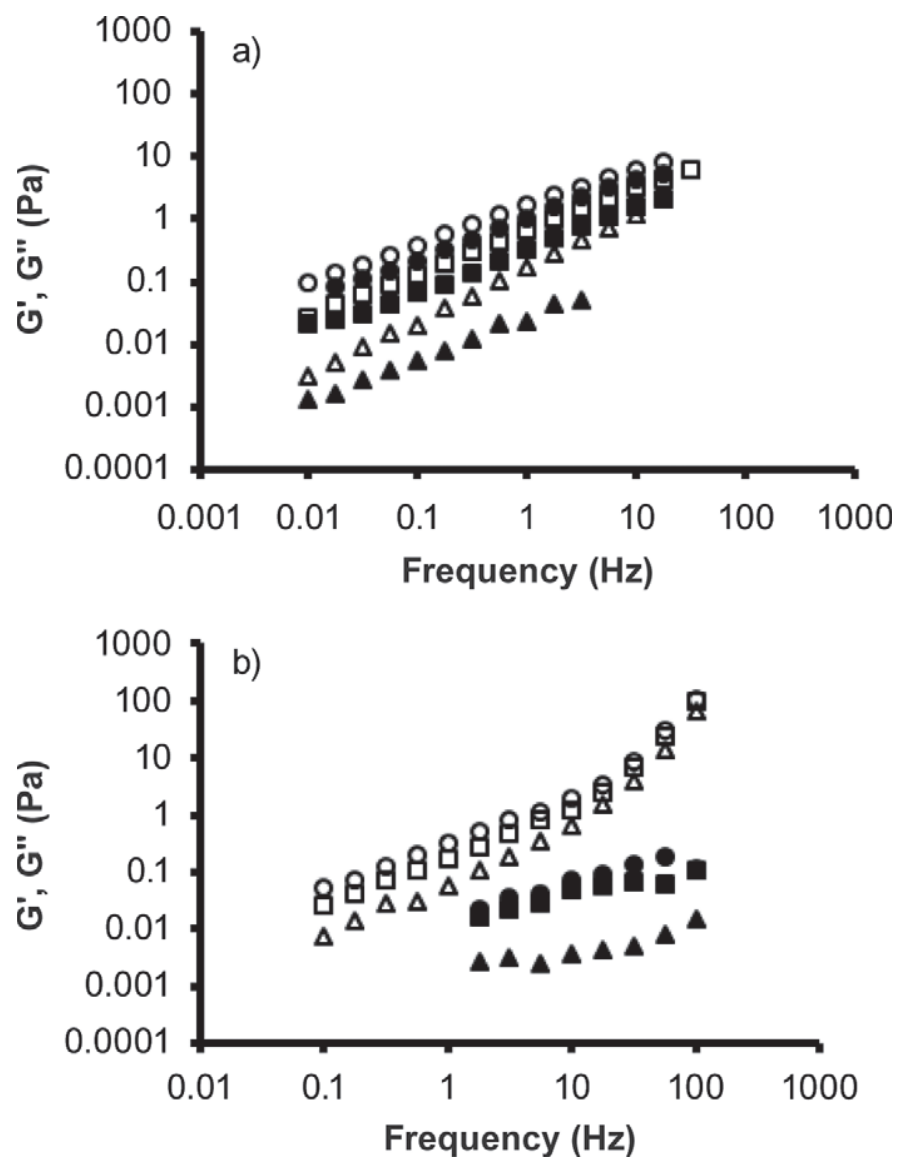

Figure 3. Oscillatory shear data for date milk beverages with 3 concentrations of gum tragacanth $(\mathrm{GT})$ at $3^{\circ} \mathrm{C}$. (a) Astragalus gossypinus; (b) Astragalus rahensis. $\mathbf{\Delta}=$ elastic modulus $\left(\mathrm{G}^{\prime}\right) 0.1 \% ; \Delta$ $=$ viscous modulus $\left(\mathrm{G}^{\prime \prime}\right) 0.1 \%$; $=\mathrm{G}^{\prime} 0.2 \% ; \square=\mathrm{G}^{\prime \prime} 0.2 \% ; \bullet=\mathrm{G}^{\prime}$ $0.3 \% ; \bigcirc=\mathrm{G}^{\prime \prime} 0.3 \%$
The higher capacity of AG to increase the consistency coefficient of the media to which it has been added might be related to the sugar composition of the AG. It was reported that $\mathrm{AG}$ contained $1 \%$ arabinose and $37 \%$ galacturonic acid, whereas AR had arabinose and galacturonic acid contents of 51 and $9 \%$, respectively (Balaghi et al., 2011). Previous studies have shown that the addition of low concentrations of gum such as pectin, xanthan, guar, locust bean gum, gelatin, and carrageenan to stabilize acidified and nonacidified dairy drinks increased the apparent viscosity and flow behavior (Lo et al., 1996; Paraskevopoulou et al., 2003; Kiani et al., 2008). Ghorbani Gorji et al. (2011) and Ghorban Shiroodi et al. (2011) investigated the effects of different types of tragacanth on the stability of doogh and kashk and found larger amounts of the less-soluble part of AG with increasing viscosity of the continuous phase and the water-soluble component, and also greater interaction with milk proteins and the mechanism of steric stability, preventing particle aggregation and creating a stable complex.

Oscillatory (dynamic) rheological properties can be used along with steady shear flow parameters to provide insight into the structure of the sample (Da Silvia and Rao, 1992; Chun and Yoo, 2004). The dependence of $\mathrm{G}^{\prime \prime}$ and $\mathrm{G}^{\prime}$ on the frequency is shown in Figure 3. For all the DMB samples, increasing the frequency increased both the $G^{\prime \prime}$ and $G^{\prime}$, with a dominating viscous modulus over the entire range of frequencies. The DMB containing AG have higher values of $G^{\prime}$ and $G^{\prime \prime}$ than those of DMB containing AR. Frequency sweeps showed a concentration dependence with $\mathrm{G}^{\prime \prime}$ and $\mathrm{G}^{\prime}$ increasing with increasing gum concentration, which might be due to more interactions occurring between polysaccharides and date milk constituents. The DMB containing AG showed $G^{\prime \prime}$ larger than $G^{\prime}$ over the entire frequency range, yet the moduli approached each other at higher frequencies. This type of behavior is indicative of a dilute solution. Yaşar et al. (2009) investigated similar results for oscillatory properties of salep drink with locust bean gum and salep glucomannan. The $\tan \delta$ values of the samples 

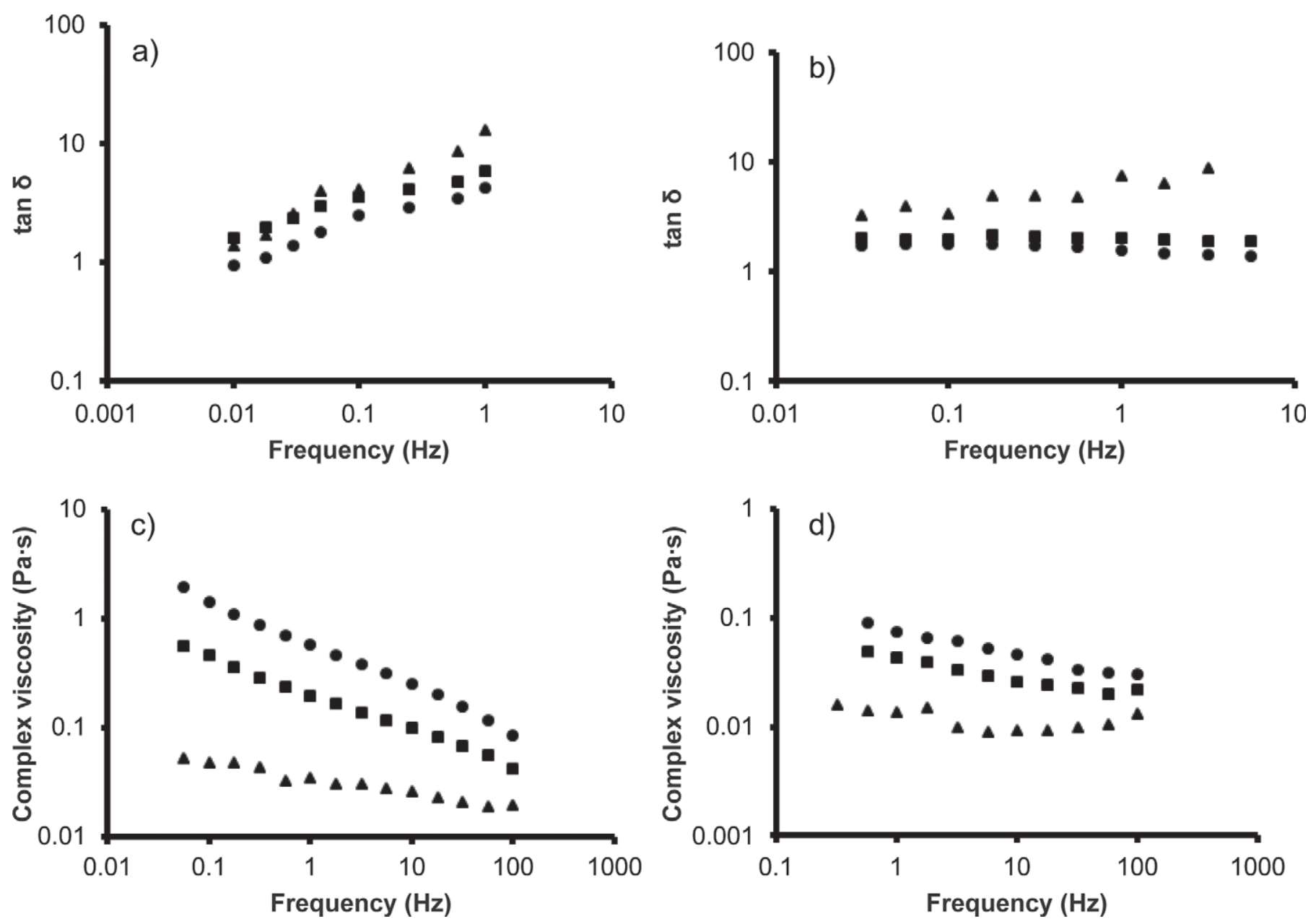

Figure 4. Oscillatory shear data for date milk beverages with 3 concentrations of gum tragacanth $(\mathrm{GT})$ at $3^{\circ} \mathrm{C}$. (a and c) Astragalus gossypinus; (b and d) Astragalus rahensis. $\boldsymbol{\Delta}=0.1 \% ; \mathbf{\square}=0.2 \% ; \bullet=0.3 \%$.

as a function of frequency are shown in Figure 4. The values of $\tan \delta$ over the range of frequency varied with GT type. For DMB containing $0.1 \%$ AG, the tan $\delta$ values were higher than $0.3 \%$ over the entire frequency range, which is indicative of the viscous character of the mixture. Increasing the AG concentration decreased the $\tan \delta$ values of $\mathrm{DMB}$, which indicates that in the system the elastic modulus was increasing and the liquid character was decreasing; however, the tan $\delta$ values were still greater than unity. As the frequency increased, the viscous character decreased and solidlike character increased (Arancibia et al., 2011). Tan $\delta$ values of $\mathrm{DMB}$ containing $\mathrm{AR}$ over the frequency range were higher than that of DMB containing AG. This indicates that AG induced more solid character or elastic nature to the system and increasing the AG concentration led the trend of the system to lower $\tan \delta$ values and, therefore, greater solid character. Basically, considering the dilution fluid and monodis- persity, the elastic modulus was more dependent on the frequency behavior and it can be concluded that the addition of GT increased the polydispersity of the particle samples. According to Figure 4, complex viscosities of the DMB containing AG over the frequency ramp was higher than that of DMB containing AR. However, the complex viscosity of the DMB containing $A G$ has more sensitivity than DMB containing AR. The complex viscosity value of DMB containing AG and DMB containing AR decreased with increased frequency, showing a non-Newtonian shear-thinning behavior. According to these results, AG has a greater ability to create structure in products. The results of previous research on the type and concentration of the gum compared with the results of the current study showed a similar trend. The pattern obtained for the mechanical range of frequency sweep was attributed to large particles of insoluble tragacanth. Those researchers found greater stability in the presence of 


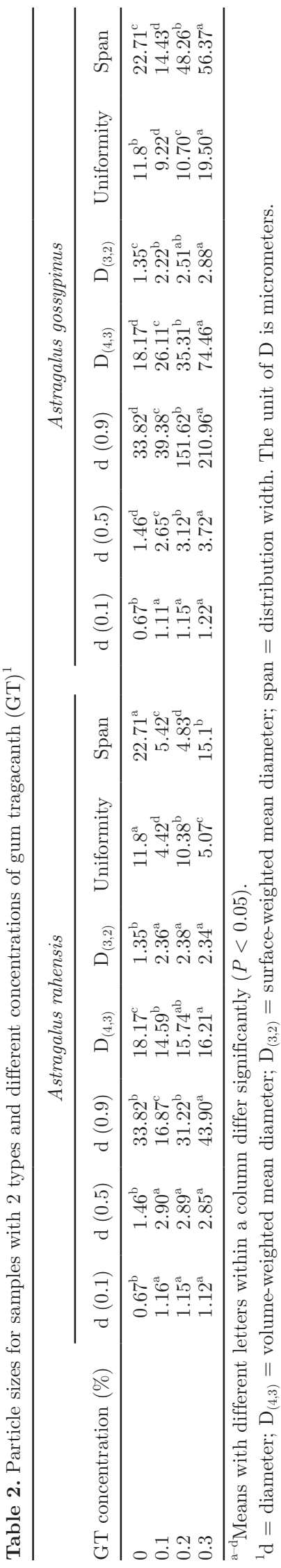

soluble protein complex formation in AG tragacanth and tragacanth solution and also the increased viscosity of the continuous phase was attributed to the insoluble tragacanth (Ghorbani Gorji et al., 2011).

\section{Particle Size Distribution}

According to Table 2, addition of DS to the plain milk changed the size distribution from monomodal to multimodal. Indeed, the particle size distribution of DMB without GT indicates 3 distinct particle size ranges in the sample (i.e., 0.3 to 10,10 to 100 , and 100 to $1,000 \mu \mathrm{m})$. It seems that the range of 100 to 1,000 $\mu \mathrm{m}$ was probably related to pulp residues, insoluble polysaccharides, and cellulosic substances of the DS. Addition of $0.1 \%$ AG to the DMB caused a drastic decrease in the volume percentage of the particles within the range of 10 to $100 \mu \mathrm{m}$, and a slight increase within the range of 100 to $1,000 \mu \mathrm{m}$. With increasing the concentration of AG from 0.1 to $0.2 \%$, a similar trend was observed. However, addition of $0.3 \%$ AG decreased the volume percentage of the particles within the range of 0.1 to $10 \mu \mathrm{m}$ and increased percentage of particles in the ranges of 10 to 100 and 100 to $1,000 \mu \mathrm{m}$; also, a small peak was observed in the range of 1,000 to $3,000 \mu \mathrm{m}$. The addition of $0.1 \%$ AG to the DMB caused a decrease in the uniformity and span values of the DMB, which indicates that the polydispersity of the system had been lowered by the addition of $0.1 \%$ AG. However, increasing the gum concentration from 0.1 to $0.3 \%$ increased the values of span and uniformity drastically and, consequently, the polydispersity was increased. Increasing the AG concentration from 0 to $0.3 \%$ increased the values of $\mathrm{d}(0.5), \mathrm{d}(0.9), \mathrm{D}_{(3,2)}$, and $\mathrm{D}_{(4,3)}$. Huang et al. (2001) similarly found that increasing the concentration of different gums such as xanthan, methyl cellulose, arabic, pectin, guar, carrageenan, and fenugreek increased the values of particle size parameters. These variations in particle size parameters could be probably explained by the absorption of AG polysaccharides onto the casein micelles of milk. Tijssen et al. (2007) found similar results by the addition of carrageenan to milk drinks. An increase in polydispersity of the system with increasing gum concentration might be evidence for slight flocculation (Tijssen et al., 2007). If only absorption occurred, an increase in size of polydispersity could not be observed. Although adding GT to DMB increased polydispersity of the system, the homogenization process would change the system toward monodispersity. According to Table 2, adding $0.1 \%$ AR to DMB increased d (0.1), d (0.5) and $\mathrm{D}_{(3,2)}$, but decreased $d(0.9)$ and $\mathrm{D}_{(4,3)}$. Increasing the concentration of the AR in the DMB did not cause significant differences in particle size parameters. The uniformity 
Table 3. Color for samples with 2 types and different concentrations of gum tragacanth $(\mathrm{GT})^{1}$

\begin{tabular}{lccccccc}
\hline \multirow{2}{*}{$\begin{array}{l}\text { GT concentration } \\
(\%)\end{array}$} & \multicolumn{3}{c}{ Astragalus rahensis } & & \multicolumn{3}{c}{ Astragalus gossypinus } \\
\cline { 2 - 3 } \cline { 5 - 7 } \cline { 5 - 7 } & $\mathrm{L}^{*}$ & $\mathrm{a}^{*}$ & $\mathrm{~b}^{*}$ & & $\mathrm{~L}^{*}$ & $\mathrm{a}^{*}$ & $\mathrm{~b}^{*}$ \\
\hline 0 & $54.53^{\mathrm{a}}$ & $3.54^{\mathrm{a}}$ & $17.05^{\mathrm{a}}$ & & $54.53^{\mathrm{a}}$ & $3.54^{\mathrm{a}}$ & $17.05^{\mathrm{a}}$ \\
0.1 & $51.01^{\mathrm{b}}$ & $2.85^{\mathrm{b}}$ & $13.59^{\mathrm{b}}$ & & $51.31^{\mathrm{b}}$ & $3.06^{\mathrm{b}}$ & $13.95^{\mathrm{b}}$ \\
0.2 & $50.27^{\mathrm{b}}$ & $2.89^{\mathrm{b}}$ & $13.59^{\mathrm{b}}$ & & $47.54^{\mathrm{c}}$ & $2.47^{\mathrm{d}}$ & $11.24^{\mathrm{c}}$ \\
0.3 & $50.72^{\mathrm{b}}$ & $2.89^{\mathrm{b}}$ & $13.44^{\mathrm{b}}$ & & $44.48^{\mathrm{d}}$ & $2.99^{\mathrm{c}}$ & $10.01^{\mathrm{d}}$ \\
\hline
\end{tabular}

${ }^{a-d}$ Means with different letters within a column differ significantly $(P<0.05)$.

${ }^{1} \mathrm{~L}^{*}$ represents lightness, $\mathrm{a}^{*}$ represents the redness-greenness quality of the color, and $\mathrm{b}^{*}$ represents the yellowness and blueness quality of the colors. For $\mathrm{L}^{*}, 100$ represents a perfect white sample and 0 a perfect black; for $\mathrm{a}^{*}$, positive values denote redness and negative values denote greenness; for $\mathrm{b}^{*}$, positive values denote yellowness and negative values denote blueness.

and span values of the samples with $\mathrm{AR}$ were much lower than of those with AG.

\section{Color Measurement}

Due to the considerable influence of the color of the products on consumer acceptance, color measurement was done on the samples. The average $\mathrm{L}^{*}, \mathrm{a}^{*}$, and $\mathrm{b}^{*}$ color data are summarized in Table 3. Addition of GT to the DMB caused the $\mathrm{L}^{*}$ values to decrease, particularly in the case of AG. The positive a* values, which represent the degree of redness within the color space, and the positive $\mathrm{b}^{*}$ values, which represent the yellowness, decreased with addition of GT to the DMB. For DMB containing AR, no significant difference existed between the $\mathrm{DMB}$ with $0.1,0.2$, and $0.3 \% \mathrm{AR}$ in terms of color parameters. However, the $\mathrm{L}^{*}, \mathrm{a}^{*}$, and $\mathrm{b}^{*}$ values differed significantly between the DMB with $0.1,0.2$, and $0.3 \%$ AG. It was previously reported that the $\mathrm{L}^{*}$ values of aqueous dispersions of AR and AG were 79.7 and 85.2, respectively, and $\mathrm{AR}$ alone gave more color to the aqueous dispersion than AG. However, according to our data, the lightness of DMB containing AG was lower than that of $\mathrm{DMB}$ containing AR. This might be attributed to the possible interactions between the polysaccharides of AG with the milk proteins of DMB, consequently forming complexes and greater particle sizes. In fact, the size of the particles of the dispersions can affect the diffraction pattern; the smaller the diffracting object is, the wider the resulting diffraction pattern becomes and vice versa. According to the Fraunhofer diffraction theory, the intensity of the light scattered by particles is proportional to the particle size. Configuration, particle size, rate of homogenization, and kind of structure are efficient factors affecting product color. Gum concentration correlated with size parameters, consistency coefficients, and color parameters; on the other hand, the difference in particle sizes of samples containing 2 types of gums could be deduced despite GT and the interaction of proteins and polysaccharides causing scattered light (Yanes et al., 2002; Arancibia et al., 2011).

\section{Sensory Evaluation}

Table 4 illustrates the average sensory evaluation results of samples with different GT concentrations in terms of appearance, flavor, odor, consistency, color, and overall preference. It was found that samples prepared with $0.2 \% \mathrm{AG}$ and $0.3 \%$ AR received the highest scores overall among other samples, but samples with $0.2 \%$ AG were chosen. Samples with $0.2 \%$ AG were more desirable than samples with $0.3 \%$ AR because $0.2 \%$ AG samples with a lower concentration had higher viscosities than samples with $0.3 \%$ AR. Hence, the comparison of viscoelastic properties of dairy beverages at low frequencies may provide relative assessment of their sensorial characteristics. The results illustrated that general acceptance of samples containing AR depended on particle size, whereas overall acceptance of samples containing AG had an inverse relationship with particle size at high concentrations.

\section{CONCLUSIONS}

Date syrup, as an innovative and attractive byproduct in date processing, and GT as a natural gum were used to formulate a flavored milk beverage with a lower amount of added sugar and no artificial flavoring agents. Sensory evaluation and instrumental rheological data revealed that using the appropriate type and concentration of GT in DMB creates desirable body, texture, and mouth feel. It seems that DMB offers a well-accepted, nutritious alternative in the wide array of beverages and potentially it can play a role in changing trends in sugar-sweetened and artificially flavored milk beverage consumption. 


\section{ACKNOWLEDGMENTS}

This study was supported by the National Nutrition and Food Technology Research Institute, Shahid Beheshti University of Medical Sciences (Tehran, Iran) and Yadollah Hashem Nazari (Iranmehr English Institute, Tehran, Iran).

\section{REFERENCES}

Al-Eid, S. M., F. M. Al-Jasass, and S. H. Hamad. 2010. Performance of baker's yeast produced using date syrup substrate on Arabic bread quality. Afr. J. Biotechnol. 9:3167-3174.

Al-Farsi, M., C. Alasalvar, M. Al-Abid, K. Al-Shoaily, M. Al-Amry, and F. Al-Rawahy. 2007. Compositional and functional characteristics of dates, syrups, and their by-products. Food Chem. 104:943-947.

Al-Hooti, S. N., J. S. Sidhu, J. M. Al-Saqer, and A. Al-Othman. 2002. Chemical composition and quality of date syrup as affected by pectinase/cellulose enzyme treatment. Food Chem. 79:215-220.

Anderson, D. M. W. 1989. Evidence for the safety of gum tragacanth (Asiatic Astragalus spp.) and modern criteria for the evaluation of food additives. Food Addit. Contam. 6:1-12.

Arancibia, C., E. Costell, and S. Bayarri. 2011. Fat replacers in lowfat carboxymethyl cellulose dairy beverages: Color, rheology, and consumer perception. J. Dairy Sci. 94:2245-2258.

Aziznia, S., A. Khosrowshahi, A. Madadlou, and J. Rahimi. 2008 Whey protein concentrate and gum tragacanth as fat replacers in nonfat yogurt: Chemical, physical, and microstructural properties. J. Dairy Sci. 91:2545-2552.

Balaghi, S., M. A. Mohammadifar, A. Zargaraan, H. A. Gavlighi, and M. Mohammadi. 2011. Compositional analysis and rheological characterization of gum tragacanth exudates from six species of Iranian Astragalus. Food Hydrocoll. 25:1775-1784.

Balaghi, S., M. A. Mohammadifar, and A. Zargaraan. 2010. Physicochemical and rheological characterization of gum tragacanth exudates from six species of Iranian Astragalus. Food Biophys. 5:59-71.

Cadena, R. S., A. G. Cruz, J. A. F. Faria, and H. M. A. Bolini. 2012. Reduced fat and sugar vanilla ice creams: Sensory profiling and external preference mapping. J. Dairy Sci. 95:4842-4850.

Chun, S. Y., and B. Yoo. 2004. Rheological behavior of cooked rice flour dispersions in steady and dynamic shear. J. Food Eng. 65:363-370.

Da Silvia, J. A. L., and M. A. Rao. 1992. Viscoelastic properties of food hydrocolloid dispersions. Pages 285-315 in Viscoelastic Properties of Foods. M. A. Rao and J. F. Steffe, ed. Elsevier, London, UK.

Dickinson, E. 1995. Mixed Biopolymers at Interfaces. Nottingham University Press, Nottingham, UK.

Dogan, M., and A. Kayacier. 2004. Rheological properties of reconstituted hot salep beverage. Int. J. Food Properties 7:683-691.

Elleuch, M., S. Besbes, O. Roiseux, C. Blecker, C. Deroanne, N.-E. Drira, and H. Attia. 2008. Date flesh: Chemical composition and characteristics of the dietary fibre. Food Chem. 111:676-682.

Everett, D. W., and R. E. McLeod. 2005. Interactions of polysaccharide stabilisers with casein aggregates in stirred skim-milk yoghurt. Int. Dairy J. 15:1175-1185.

Frary, C. D., K. Rachel, R. K. Johnson, and M. Q. Wang. 2004. Children and adolescents' choices of foods and beverages high in added sugars are associated with intakes of key nutrients and food groups. J. Adolesc. Health 34:56-63.

Gatade, A. A., R. C. Ranveer, and A. K. Sahoo. 2009. Physico-chemical and sensorial characteristics of chocolate prepared from soymilk. Adv. J. Food Sci. Technol. 1:1-5.

Ghorbani Gorji, E., M. A. Mohammadifar, H. Ezzatpanah, and A. M. Mortazavian. 2011. Influence of three types of Iranian gum tragacanths on rheological properties and stabilization of fat-free doogh, an Iranian yoghurt drink. Ir. J. Nutr. Sci. Food Technol. 6:31-42. 
Ghorban Shiroodi, S., M. A. Mohammadifar, E. Ghorbani Gorji, H. Ezzatpanah, and N. Zohouri. 2011. Influence of gum tragacanth on physicochemical and rheological properties of kashk. J. Dairy Res. 79:93-101.

Gilchrist, A., and J. Nobbs. 2000. Colorimetry, Theory. Pages 340-342 in Encyclopedia of Spectroscopy and Spectrometry. Vol. 1. J. C. Lindon, G. E. Tranter, and J. L. Holmes, ed. Academic Press, London, UK and San Diego, CA.

Glicksman, M. 1983. Food Hydrocolloids. CRC Press, Boca Raton, FL.

González-Tomás, L., S. Bayarri, and E. Costell. 2009. Inulin-enriched dairy desserts: Physicochemical and sensory aspects. J. Dairy Sci. 92:4188-4199.

Grindrod, J., and T. A. Nickerson. 1968. Effect of various gums on skimmilk and purified milk proteins. J. Dairy Sci. 51:834-841.

Hansen, P. M. T. 1993. Food hydrocolloids in the dairy industry. Pages 211-224 in Food hydrocolloids: Structures, Properties and Functions. K. Nishinari and E. Doi, ed. Plenum Press, New York, NY.

Hatami, M., M. Nejatian, and M. A. Mohammadifar. 2012. Effect of co-solute and gelation temperature on milk protein and gum tragacanth interaction in acidified gel. Int. J. Biol. Macromol. 50:1109-1115.

Hobani, A. I. 1998. Rheological behaviour of date-water concentrates. J. Food Eng. 36:349-357.

Hollowood, T. A., R. S. T. Linforth, and A. J. Taylor. 2002. The effect of viscosity on the perception of flavour. Chem. Senses 27:583-591.

Huang, X., Y. Kakuda, and W. Cui. 2001. Hydrocolloids in emulsions: Particle size distribution and interfacial activity. Food Hydrocoll. 15:533-542.

Kiani, H., S. M. A. Mousavi, and Z. Emam-Djomeh. 2008. Rheological properties of Iranian yoghurt drink, doogh. Int. J. Dairy Sci. $3: 71-78$.

Köksoy, A., and M. Kılıç. 2003. Effect of water and salt level on rheological properties of ayran, a Turkish yoghurt drink. Int. Dairy J. $13: 835-839$.

Kranz, S., H. Smiciklas-Wright, A. M. Siega-Riz, and D. Mitchell. 2004. Adverse effect of high added sugar consumption on dietary intake in American preschoolers. J. Pediatr. 146:105-111.

Lo, C. G., K. D. Lee, R. L. Richter, and C. W. Dill. 1996. Influence of guar gum on the distribution of some flavor compounds in acidified milk products. J. Dairy Sci. 79:2081-2090.

McClements, D. J. 2005. Food Emulsions: Principles, Practices, and Techniques. CRC Press, Boca Raton, FL.

Metzger, T. G. 2006. The Rheology Handbook for Users of Rotational and Oscillatory Rheometers. 2nd ed. Vincentz Network, Hannover, Germany.

Milani, E., and A. Koocheki. 2011. The effect of date syrup and guar gum on physical, rheological and sensory properties of low fat frozen yoghurt dessert. Int. J. Dairy Technol. 64:121-129.

Mohammadifar, M. A., S. M. Musavi, A. Kiumarsi, and P. A. Williams. 2006. Solution properties of targacanthin (water-soluble part of gum tragacanth exudate from Astragalus gossypinus). Int. J. Biol. Macromol. 38:31-39.
Mollet, H. 2001. Food formulations. Pages 375-388 in Formulation Technology: Emulations, Suspensions, Solid Forms. Wiley-VCH Verlag GmbH, Weinheim, Germany.

Paraskevopoulou, A., I. Athanasiadis, G. Blekas, A. A. Koutinas, M. Kanellaki, and V. Kiosseoglou. 2003. Influence of polysaccharide addition on stability of a cheese whey kefir-milk mixture. Food Hydrocoll. 17:615-620.

Razavi, S. M. A., M. B. Habibi Najafi, and Z. Alaee. 2007. The time independent rheological properties of low fat sesame paste/date syrup blends as a function of fat substitutes and temperature. Food Hydrocoll. 21:198-202.

Samavati, V., E. Emam-Djomeh, M. A. Mohammadifar, M. Omid, and A. Mehdinia. 2011. Influence of tragacanth gum exudates from specie of Astragalus gossypinus on rheological and physical properties of whey protein isolate stabilised emulsions. Int. J. Food Sci. Technol. 46:1636-1645.

Schmitt, C., C. Sanchez, F. Thomas, and J. Hardy. 1999. Complex coacervation between $\beta$-lactoglobulin and acacia gum in aqueous medium. Food Hydrocoll. 13:483-496.

Sidhu, J. S., J. M. Al-Saqer, S. N. Al-Hooti, and A. Al-Othman. 2003. Quality of pan bread made by replacing sucrose with date syrup produced by using pectinase/cellulase enzymes. Plant Foods Hum. Nutr. 58:1-8.

Snoeren, T. H. M., T. A. J. Payens, J. Jeunink, and P. Both. 1975 Electrostatic interaction between kappa-carrageenan and kappacasein. Milchwissenschaft 30:393-396.

Spagnuolo, P. A., D. G. Dalgleish, H. D. Goff, and E. R. Morris. 2005. Kappa-carrageenan interactions in systems containing casein micelles and polysaccharide stabilizers. Food Hydrocoll. 19:371-377.

Steffe, J. F. 1996. Rheological Methods in Food Process Engineering. Freeman Press, East Lansing, MI.

Telcioglu, A., and A. Kayacier. 2007. The effect of sweeteners and milk type on the rheological properties of reduced calories salep drink. Afr. J. Biotechnol. 6:465-469.

Tijssen, R. L. M., L. S. Canabady-Rochelle, and M. Mellema. 2007. Gelation upon long storage of milk drinks with carrageenan. J. Dairy Sci. 90:2604-2611.

Tufail, F., I. Pasha, M. S. Butt, N. Abbas, and S. Afzaal. 2002. Use of date syrup in the preparation of low caloric cakes replacing sucrose. Pak. J. Agric. Sci. 39:149-153.

Watts, B. M., G. L. Ylimaki, L. E. Jeffrey, and L. G. Elias. 1989. Hedonic tests. Pages 66-79 in Basic Sensory Methods for Food Evaluation. International Development Research Center, Ottawa, Ontario, Canada.

Weinbreck, F. 2004. Whey protein/polysaccharide coacervates: Structure and dynamics. Doctoral Diss. Utrecht University, Utrecht, the Netherlands.

Yanes, M., L. Durán, and E. Costell. 2002. Rheological and optical properties of commercial chocolate milk beverages. J. Food Eng. $51: 229-234$.

Yaşar, K. T. K., and N. Şahan. 2009. Dynamic rheological characterization of salep glucmannan/galactomannan-based milk beverages. Food Hydrocoll. 23:1305-1311. 